\title{
Effect of Incorporation of Disinfectants on Surface Hardness and Dimensional Accuracy of Die Stone: An in vitro Study
}

\author{
${ }^{1}$ Anubhuti Bakshi, ${ }^{2}$ Rajat Dang
}

\begin{abstract}
Aim: To evaluate surface hardness and dimensional accuracy of type IV dental stone after incorporation of disinfectants.
\end{abstract}

Materials and methods: A total of 100 specimens, $50(40 \mathrm{~mm}$ $\times 10 \mathrm{~mm}$ ) disk shaped and 50 frustum cone shaped, were fabricated from type IV dental stone after incorporation of various disinfectants, namely glutaraldehyde (2\%), iodophor (1.76\%), chlorhexidine (2\%), and sodium hypochlorite (1\%), for evaluation of surface hardness and dimensional accuracy. Surface hardness was tested after 1- and 24-hour time interval using Rockwell hardness testing machine. Dimensional accuracy was measured using traveling microscope. Data obtained were compiled and analyzed statistically by using analysis of variance and post hoc test.

Results: Results showed significant decrease in surface hardness of samples incorporated with disinfectants at 1 hour as compared with control (distilled water). Surface hardness of all the samples increased with time and was almost equal to control group at 24-hour interval, with iodophor showing the maximum value in comparison with the other disinfectants used. When dimensional accuracy of all the groups was compared, iodophor and sodium hypochlorite were found to cause negative alterations.

Conclusion: Within the limitations of this in vitro study, it was concluded that incorporation of disinfectants in die stone during mixing did not affect the hardness value at 24-hour interval. Dimensional accuracy was altered by iodophor and sodium hypochlorite, but remained unaffected by chlorhexidine and glutaraldehyde.

Keywords: Dental impression, Dimensional accuracy, Disinfection, Immersion, Surface hardness.

How to cite this article: Bakshi A, Dang R. Effect of Incorporation of Disinfectants on Surface Hardness and Dimensional Accuracy of Die Stone: An in vitro Study. Int J Prosthodont Restor Dent 2017;7(3):86-91.

Source of support: Nil

Conflict of interest: None

\footnotetext{
${ }^{1}$ Postgraduate Student, ${ }^{2}$ Professor

${ }^{1,2}$ Department of Prosthodontics, Maharishi Markandeshwar College of Dental Sciences and Research, Ambala, Haryana India

Corresponding Author: Rajat Dang, Professor, Department of Prosthodontics, Maharishi Markandeshwar College of Dental Sciences and Research, Ambala, Haryana, India, Phone: +919501008837, e-mail: drrajatdang@gmail.com
}

\section{INTRODUCTION}

The oral environment shelters various beneficial and harmful microorganisms in the saliva and blood. In prosthodontics, making impressions is a routine procedure, and impression materials come in direct contact with the oral fluids, such as blood and saliva, which may contain disease-causing microbes. According to a study done by Powell et al, ${ }_{1}$ presence of numerous microorganisms, such as Enterobacter cloacae, Escherichia coli, and Klebsiella oxytoca was reported in $67 \%$ of the samples sent. Evaluation of the microorganisms present on the impression and the surface of the casts was done by Leung and Schonfeld, ${ }^{2}$ and they demonstrated high risk of crosscontamination. It has been shown that the stone casts that are poured from the impression are a major cause of cross-contamination between patients and dentists. ${ }^{3}$ Hence, disinfection of casts is mandatory.

The American Dental Association ${ }^{4}$ recommended various procedures for the disinfection of the cast, which includes use of disinfectant sprays, immersion in disinfectant solutions, incorporation of disinfectants at the time of mixing, and ethylene oxide gas sterilization without altering the dimensional accuracy of the casts prior to transferring to the dental laboratories.

Rudd et $\mathrm{al}^{5}$ demonstrated changes in surface properties by immersing the cast for 15 minutes in tap water. It is advised to immerse the cast for at least 30 minutes to attain surface disinfection. ${ }^{4}$ Spray technique for disinfection of cast seems to erase the surface details.

The biggest drawback of the spray technique was incapability to remain in complete contact with the surfaces of cast for the desired time period including undercuts and interproximal surfaces. Therefore, to eliminate the problems associated with these two techniques, it was recommended to incorporate some chemicals into the stone before pouring of the cast at the time of mixing, so as to disinfect both cast and impression. The disinfecting agent should not only be effective against microbes, but it should also not degrade the physical properties of the gypsum cast. ${ }^{6}$ Hence, this study was conducted to evaluate and compare the effect of incorporation of disinfectants on surface hardness and dimensional accuracy of die stone. 


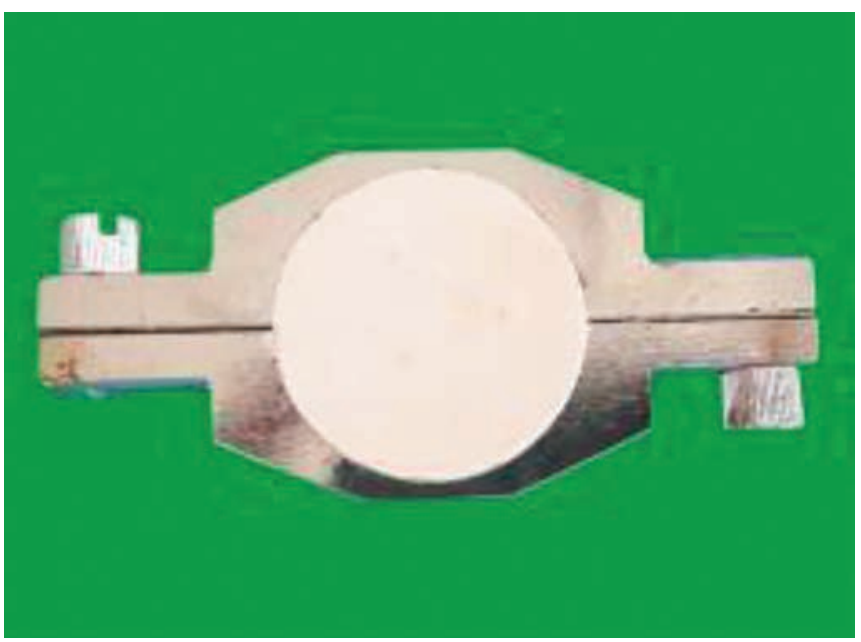

Fig. 1: Sample preparation for surface hardness

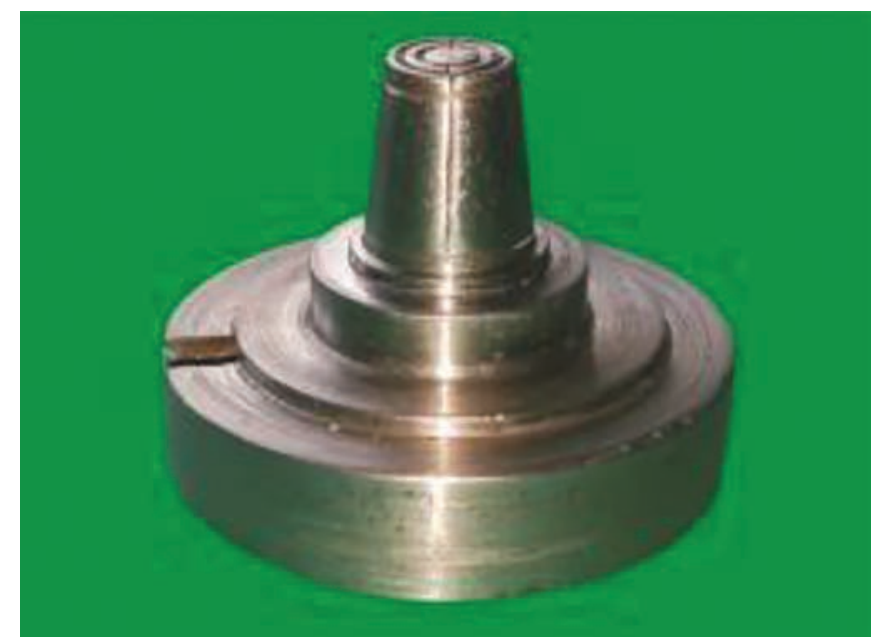

Fig. 3: Master die was fabricated according to ADA specification No. 19, for dimensional accuracy

\section{MATERIALS AND METHODS}

The surface hardness and dimensional accuracy of type IV dental stone were evaluated after incorporation of disinfectants namely chlorhexidine $2 \%$, iodophor $1.76 \%$, glutaraldehyde $2 \%$, and sodium hypochlorite $1 \%$ at the time of mixing. A total of 100 samples were prepared. About 50 disc-shaped $(40 \mathrm{~mm} \times 10 \mathrm{~mm})$ samples were made for surface hardness and were subdivided into five different groups (Figs 1 and 2):

1. Group I: Control in which die stone was mixed with distilled water

2. Group II: $50 \%$ of chlorhexidine (2\%) in $50 \%$ water

3. Group III: $50 \%$ of iodophor $(1.76 \%)$ in $50 \%$ water

4. Group IV: $50 \%$ of glutaraldehyde (2\%) in $50 \%$ water

5. Group $V: 50 \%$ of sodium hypochlorite (1\%) in $50 \%$ water

Samples were subjected to Rockwell hardness testing after 1 and 24 hours to evaluate surface hardness. Results showed that surface hardness of die stone after 1 hour was greater in control group as compared with all the other

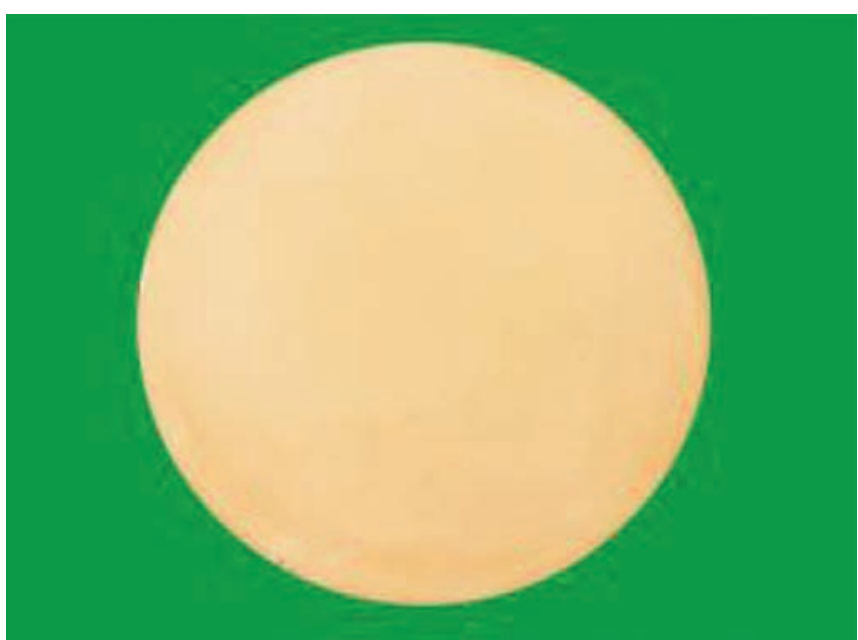

Fig. 2: Surface hardness sample for testing surface hardness after 1 and 24 hours

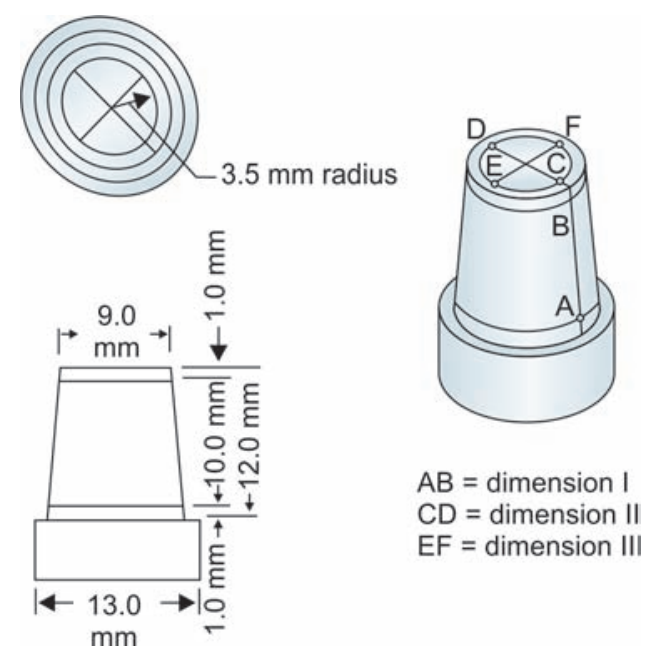

Fig. 4: Specifications of die for dimensional accuracy

groups. However, after 24 hours, surface hardness of all the groups including control was almost equal except for sodium hypochlorite, which showed significant decrease in surface hardness of die stone.

The rest of the 50 samples (frustum of cone shaped) were made to evaluate dimensional accuracy and were divided into five groups (Fig. 3).

1. Group I: Control in which die stone was mixed with distilled water.

2. Group II: $50 \%$ of iodophor (1.76\%) in 50\% water.

3. Group III: $50 \%$ of glutaraldehyde (2\%) in $50 \%$ water.

4. Group IV: $50 \%$ of sodium hypochlorite (1\%) in $50 \%$ water

5. Group V: $50 \%$ of chlorhexidine (2\%) in $50 \%$ water.

Each group for dimensional accuracy was measured for Dimension I, the distance between reference mark A and B, Dimension II, the distance between reference mark C and D, Dimension III, the distance between reference mark E and F. The measurements were repeated three times to determine the mean for each dimension (Fig. 4). 


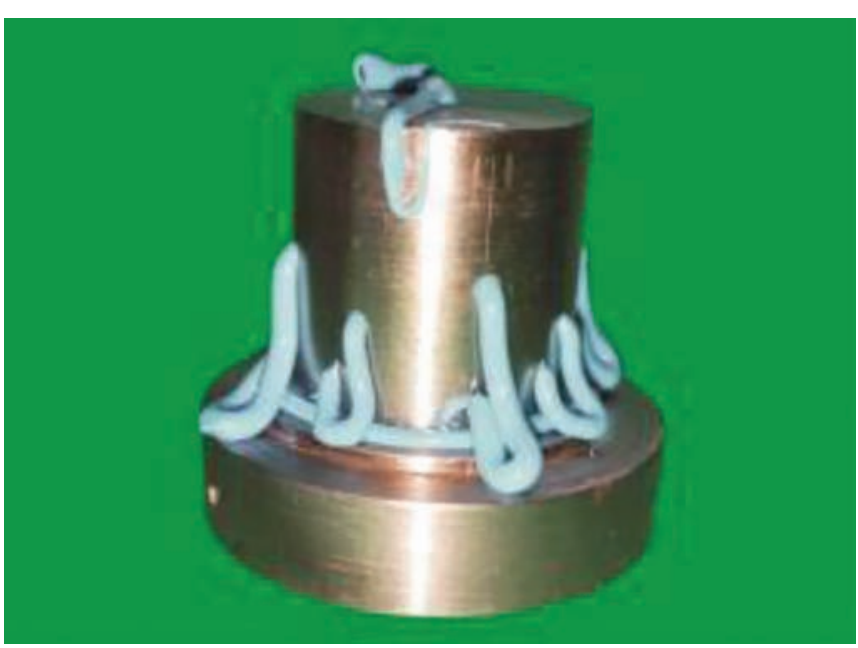

Fig. 5: Impression of the die was made

The impression of the die was made using medium body polyvinyl siloxane impression material loaded in custom-made metal mold (Fig. 5). The die stone was hand mixed for 45 seconds, and the mixture was vibrated and poured into the impression. The stone was allowed to set for 1 hour at ambient room temperature. After setting, the cylindrical samples were removed from the molds (Fig. 6). Readings were made using traveling microscope (Fig. 7).

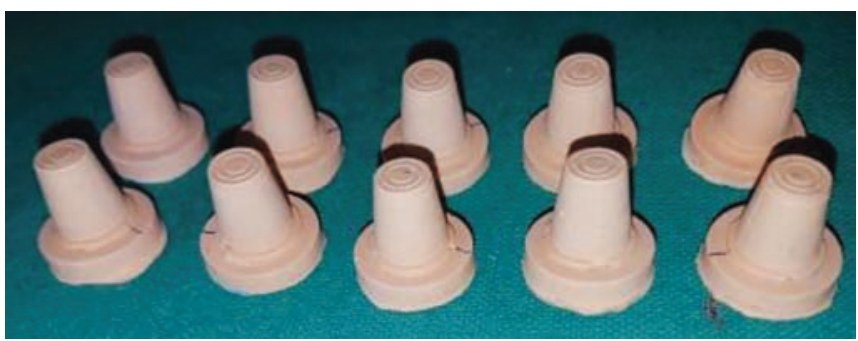

Fig. 6: Samples obtained after pouring die stone in the impression

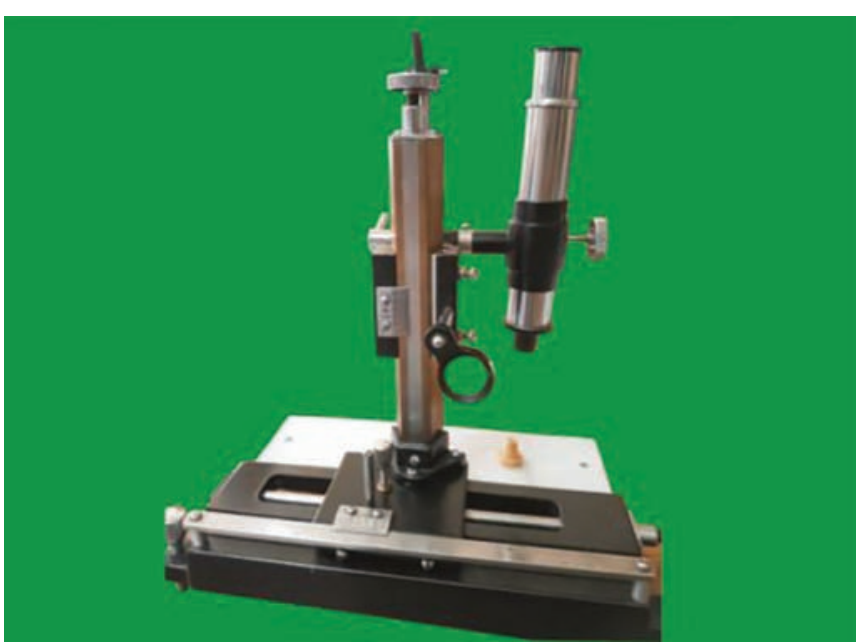

Fig. 7: Samples subjected under traveling microscope to evaluate dimensional accuracy

\section{RESULTS}

Results show highly significant difference in surface hardness values of all the groups when compared with control group (Table 1). Iodophor showed maximum decrease in hardness value, while minimum change was seen in chlorhexidine (Table 2). Surface hardness was maximum after 24 hours (Graph 1). For dimensional accuracy, iodophor and sodium hypochlorite showed the maximum dimensional change, while no dimensional change was seen in chlorhexidine and glutaraldehyde (Table 3).

Table 1: Mean and standard deviation (SD) of surface hardness at 1 hour

\begin{tabular}{lllll}
\hline Surface hardness at 1 hour & $n$ & Mean & SD & $\begin{array}{l}\text { Standard } \\
\text { error }\end{array}$ \\
\hline Group I: control & 10 & 79.503 & 3.6965 & 1.16889 \\
Group II: 2\% chlorhexidine & 10 & 66.138 & 3.7574 & 1.1882 \\
Group III: 1.76\% iodophor & 10 & 58.368 & 2.8214 & 0.8922 \\
Group IV: 2\% glutaraldehyde & 10 & 60.014 & 2.7011 & 0.8542 \\
$\begin{array}{l}\text { Group V: 1\% sodium } \\
\text { hypochlorite }\end{array}$ & 10 & 63.665 & 2.9208 & 0.9237
\end{tabular}

SD: Standard deviation

Table 2: Mean and standard deviation (SD) of surface hardness at 24 hours

\begin{tabular}{lllll}
\hline $\begin{array}{l}\text { Surface hardness at } \\
\text { 24 hours }\end{array}$ & $n$ & Mean & SD & $\begin{array}{l}\text { Standard } \\
\text { error }\end{array}$ \\
\hline Group I: control & 10 & 91.537 & 2.8949 & 0.9154 \\
Group II: $2 \%$ chlorhexidine & 10 & 86.989 & 3.0681 & 0.9702 \\
Group III: $1.76 \%$ iodophor & 10 & 91.335 & 3.6665 & 1.1594 \\
Group IV: $2 \%$ glutaraldehyde & 10 & 88.870 & 5.0872 & 1.6087 \\
$\begin{array}{l}\text { Group V: } 1 \% \text { sodium } \\
\text { hypochlorite }\end{array}$ & 10 & 83.173 & 4.9790 & 1.5745
\end{tabular}

SD: Standard deviation

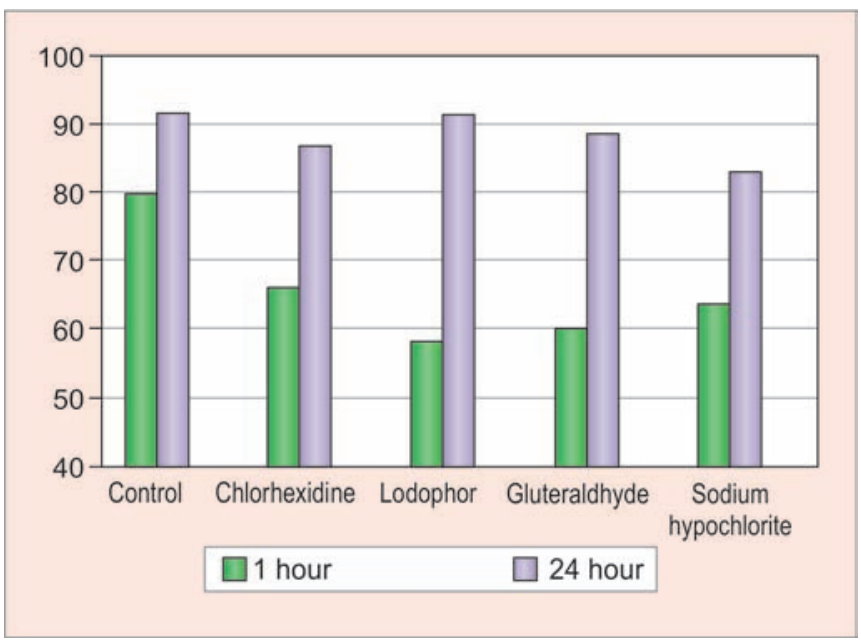

Graph 1: Mean of surface hardness at 1 and 24 hours 
Table 3: Statistical comparison between mean and standard deviation (SD) for dimensional accuracy of die stone after incorporation of various disinfectants

\begin{tabular}{|c|c|c|c|c|c|}
\hline & & $n$ & Mean & $S D$ & $\begin{array}{l}\text { Standard } \\
\text { error }\end{array}$ \\
\hline \multirow{5}{*}{$A B$} & Control & 10 & 10.0100 & 0.03018 & 0.00955 \\
\hline & lodophor & 10 & 9.5840 & 0.08566 & 0.02709 \\
\hline & Glutaraldehyde & 10 & 10.0010 & 0.04606 & 0.01456 \\
\hline & Sodium hypochlorite & 10 & 9.6240 & 0.09559 & 0.03023 \\
\hline & Chlorhexidine & 10 & 10.0000 & 0.02708 & 0.00856 \\
\hline \multirow{5}{*}{ CD } & Control & 10 & 7.0150 & 0.02915 & 0.00922 \\
\hline & Iodophor & 10 & 6.3330 & 0.14072 & 0.04450 \\
\hline & Glutaraldehyde & 10 & 7.0100 & 0.02582 & 0.00816 \\
\hline & Sodium hypochlorite & 10 & 6.6130 & 0.11576 & 0.03661 \\
\hline & Chlorhexidine & 10 & 7.0105 & 0.03387 & 0.01071 \\
\hline \multirow{5}{*}{ EF } & Control & 10 & 7.0180 & 0.03084 & 0.00975 \\
\hline & Iodophor & 10 & 6.4750 & 0.18793 & 0.05943 \\
\hline & Glutaraldehyde & 10 & 7.0007 & 0.04922 & 0.01556 \\
\hline & Sodium hypochlorite & 10 & 6.5910 & 0.12749 & 0.04032 \\
\hline & Chlorhexidine & 10 & 7.0060 & 0.03688 & 0.01166 \\
\hline
\end{tabular}

SD: Standard deviation

\section{DISCUSSION}

Cross-contamination in dental practice is an issue to be dealt among the dental auxiliaries and the patients. Due to the wide spread of various immunodeficiency diseases, there is an urgent need to maintain a hygienic dental environment. ${ }^{7}$ Studies have shown that there is significant and acceptable reduction in the number of bacteria when disinfectants were incorporated into the gypsum during its mixing. ${ }^{8}$ This shows that incorporation of disinfectants to gypsum may be a helpful method for the disinfection of both cast and impression. ${ }^{9}$

All disinfectants have their pros and cons. For example, glutaraldehyde ${ }^{10}$ has been proved to be sporicidal, viricidal, fungicidal, and bactericidal. However, it should not be used as a spray disinfectant as the fumes are toxic. They readily reach the lethal level and may cause allergy and other undesired reactions to dental personnel handling them.

Iodophors are loose complexes of iodine bound to synthetic carriers, such as povidone. It is an intermediatelevel disinfectant, which may not inactivate spores, but will destroy other microbes, tubercle bacilli in particular.

Sodium hypochlorite is inexpensive and a very effective disinfectant. It is recommended for hepatitis B and human immunodeficiency virus by the Centers for Disease Control and Prevention. However, caution should be exercised during use because sodium hypochlorite is corrosive to metals. ${ }^{11}$

Chlorhexidine $^{12}$ is a cationic bisbiguanide agent and has broad antibacterial spectrum against bacteria, viruses and also has antifungal activities. It is harmonious with the oral tissue. It has the capability to stay on surface and is incrementally released. Due to its magnificent properties, its use in dentistry is increasing.

To determine surface hardness, stainless steel die (40 $\mathrm{mm} \times 10 \mathrm{~mm}$ ) was fabricated according to American Dental Association (ADA) specification No. 25 and samples were tested using Rockwell hardness testing machine. The results showed that the surface hardness of sample was high at the time interval of 24 hours as compared with the surface hardness of sample at 1 hour, except for sodium hypochlorite, which showed maximum decrease in surface hardness. Ivonovski et $\mathrm{al}^{13}$ "reported a reduction in compressive strength after the incorporation of sodium hypochlorite as disinfecting agent." Abdelaziz et $\mathrm{al}^{14}$ also reported a reduction in compressive and tensile strengths of types III and V dental stone after the incorporation of sodium hypochlorite. It is assumed that sodium ions from the sodium hypochlorite interfere with calcium compounds in the gypsum structure and affect its strength. Sodium hypochlorite may alter the crystalline structure that could alter the crystals ability to intermesh. ${ }^{15}$

The probable explanation for increase in surface hardness with time may be that, the amount of liquid used to mix the powder particles is greater than the actual amount required for chemical reaction. The water used in addition to that necessary for chemical reaction is called excess water. The excess water does not react with the powder particles and serves only to wet the powder particles. This excess water is lost by evaporation as the time passes and as the last traces of liquid evaporates, the fine particles of the gypsum precipitate to anchor the large crystals, and hardness reaches to its maximum in 24 hours. ${ }^{16}$

Surface hardness of the sample obtained from distilled water was found to be maximum, but as time passes, the surface hardness of all the samples obtained from mixing with different solutions, including distilled water, increased and became almost equal at the 24-hour interval. The possible explanation for difference in the surface hardness of sample obtained by mixing with different disinfectant solutions compared with that of control group at 1-hour interval may be related to the retention of solutions. Any retention of solution longer than the retention of water would have a weakening effect on the sample and the surface hardness will be less in such situations.

The probable explanation for decrease in surface hardness of glutaraldehyde as compared with control may be the porosity within the set material. Ivanovski et $\mathrm{al}^{13}$ concluded that glutaraldehyde evaporates from the mixed material, leading to incomplete solubility of some of the hemihydrate particles. ${ }^{17}$

The results of this study are in accordance with those of Mahler, ${ }^{18}$ Abdelaziz et al, ${ }^{14}$ Roy et al, ${ }^{12}$ Ivanovski et al, ${ }^{13}$ Mensfield et al, ${ }^{19}$ and Sabouhi et al, ${ }^{20}$ who stated a 
decrease in surface hardness of die stone after incorporation of disinfectants.

For the analysis of dimensional accuracy, the master die fabricated simulates a tapered tooth preparation. The method used scribed lines for measurements in buccolingual and mesiodistal dimensions, similar to ADA specification No. 19. The method also adds a third measurement to simulate the occlusogingival dimension.

Depending upon the composition of the gypsum and the calcination process, expansion varying between 0.06 and $0.5 \%$ of the total volume is expected. By interpreting data obtained in this study, it was observed that results of control group were similar to the other groups except for iodophor and sodium hypochlorite, which adversely affected the dimensional accuracy. It may be because of the reason that these materials, i.e., sodium hypochlorite and iodophor, altered the characteristics of expansion and, as a result of that, led to the contraction of the material during setting. ${ }^{21}$ The results of this study are in accordance with the study done by Abdelaziz et al, ${ }^{14}$ who reported a significant change in dimensional accuracy of type III and type IV dental stone after incorporation of sodium hypochlorite and iodophor as water substitutes in dental stone.

Initially, expansion occurs during the setting of gypsum because dihydrate crystals show thrusting action. During this process of conversion of hemihydrate into dihydrate, crystals grow and the branches so formed create pressure against the adjacent crystals leading to volumetric expansion. This dimensional change is favorable to compensate for metal-resulted solidification shrinkage and dimensional inaccuracies of wax pattern and casting process. The inclusion of sodium hypochlorite and iodophor in gypsum products results in a reduction of setting expansion. These findings were probably due to different solubility rates of hemihydrate that alters the crystal growth and the amount of outward thrust. The results of the present study disagree with those of Breault et $\mathrm{al}^{22}$ and Abdelaziz et al, ${ }^{14}$ who reported no significant change in dimensional accuracy when incorporating chemical disinfectants. This may be due to different composition of materials (5.23\% sodium hypochlorite) used and the results are in favor of study done by Sfarghiu et al, ${ }^{23}$ who reported negative alteration in dimensional accuracy set model after incorporation of $1 \%$ sodium hypochlorite, and no alteration was seen in die stone incorporated with $2 \%$ chlorhexidine.

\section{CONCLUSION}

Based on the observation and results of this study, following conclusions are made:

- Surface hardness of die stone decreased after 1 hour of mixing with chemical disinfectants.

- Surface hardness value of all the groups was almost equal to control group at 24-hour interval.
- The hardness of specimens obtained by mixing with iodophor was found to be maximum at 24-hour interval in comparison with the other disinfectants that were used.

- When dimensional accuracy was compared, chlorhexidine and glutaraldehyde showed results similar to that of control group.

- Sodium hypochlorite and iodophor negatively altered the dimensional accuracy of the set model.

\section{REFERENCES}

1. Powell GL, Runnells RD, Saxon BA, Whisenant BK. The presence and identification of organisms transmitted to dental laboratories. J Prosthet Dent 1990 Aug;64(2):324-325.

2. Leung RL, Schonfeld SE. Gypsum cast as a potential source of microbial contamination. J Prosthetic Dent 1983 Feb;49(2): 210-211.

3. Mitchell DL, Hariri NM, Duncanson MG Jr, Jacobsen NL, McCallum RE. Quantitative study of bacterial colonization of dental casts. J Prosthet Dent 1997 Nov;78(5):518-521.

4. American Dental Association. Infection control recommendations for the dental office and dental laboratory. J Am Dent Assoc 1996 May;127(5):672-680.

5. Rudd KD, Morrow RW, Brown CE Jr, Powell JM, Rahe AJ. Comparison of effects of tap water and slurry water on gypsum casts. J Prosthet Dent 1970 Nov;24(5):563-570.

6. Guiraldo RD, Borsato TT, Berger SB, Lopes MB, Gonini-Jr A, Sinhoreti MA. Surface detail reproduction and dimensional accuracy of stone models: influence of disinfectant solutions and alginate impression materials. Braz Dent J 2012;23(4):417-421.

6. Twomey JO, Khalid MA, Combe EC, Anderson DL. Calcium hypochlorite as a disinfecting additive for dental stone. J Prosthet Dent 2003 Sep;90(3):282-288.

7. Anusavice, KJ. Phillips' science of dental materials. 10th ed. Philadelphia (PA): W.B. Saunders Company; 1996. p. 189-191.

8. Taylor RL, Wright OS, Maryan C. Disinfection procedures: their effect on the dimensional accuracy and surface quality of irreversible hydrocolloid impression materials and gypsum casts. Dent Mater 2002 Mar;18(2):103-110.

9. Tebrock OC, Engelmeier RL, Mayfield TG, Adams HJ. Managing dental impressions and casts of patients with communicable diseases. Gen Dent 1989 Nov-Dec;37(6):490-495.

10. Kumar RN, Reddy SM, Karthigeyan S, Punithavathy R, Karthik KS, Manikandan R. The effect of repeated immersion of gypsum cast in sodium hypochlorite and glutaraldehyde on its physical properties: an in vitro study. J Pharm Bioallied Sci 2012 Aug;4(Suppl 2):S353-S357.

11. Abdullah MA. Surface detail, compressive strength, and dimensional accuracy of gypsum casts after repeated immersion in hypochlorite solution. J Prosthet Dent 2006 Jun;95(6):462-468.

12. Roy SM, Sridev J. An evaluation of the mechanical properties of Type III and Type IV gypsum mixed with two disinfectant solutions. Indian J Dent Res 2010;21(3):374-379

13. Ivanovski S, Svage NW, Brockhurst PJ, Bird PS. Disinfection of dental stone cast : Antimicrobial effects and physical property alterations. Dent Mater 1995 Jan;11(1):19-23

14. Abdelaziz KM, Attia A. Evaluation of disinfected casts poured in gypsum with gum Arabic and calcium hydroxide additives. J Prosthet Dent 2004;92(1):27-32. 
15. Schutt RW. Bactericidal effect of a disinfectant dental stone on irreversible hydrocolloid impressions and Stone casts. J Prosthet Dent 1989 Nov;62(5):605-607.

16. Sarma AC, Robert N. A study on the effect of disinfectant chemicals on physical properties of die stone. Quintessence Int 1990 Jan;21(1):53-59.

17. Mansfield SM, White JM. Antimicrobial effects from incorporation of disinfectants into gypsum casts. Int J Prosthodont 1991 Mar-Apr;4:(2)180-185.

18. Mahler DB. Hardness and flow properties of gypsum materials. J Prosthet Dent 1951;1:188-195.

19. Mansfield SM, White JM. Antimicrobial effects from incorporation of disinfectants into gypsum casts. Int J Prosthodont 1991 Mar-Apr;4(2):180-185.
20. Sabouhi M, Khodaeian N, Ataei E, Kiani F. The effect of addition of calcium hypochlorite disinfectant on setting expansion and surface hardness of dental stone. J Islamic Dent Assoc Iran (JIDA) 2014 May;26(1):21-25.

21. Revised American Dental Association specification No. 19 for Non Aqueous, Elastomeric impression materials. J Am Dent Assoc 1977;94:733-741.

22. Breault LG, Paul JR, Hondrum SO, Christensen LC. Die stone disinfection: Incorporation of sodium hypochlorite. J Prosthodont 1998;1:13-16.

23. Sfarghiu GL, Oancea L, Lițescu R, Burlibașa M, Moraru L, Perieanu VȘ, Marcov N, Ionescu C, Perieanu MV, Popșor S, et al. The influence of disinfectant incorporation on die stone linear expansion. Rom Biotechnol Lett 2016 Jan;21(3):11585-11590. 